
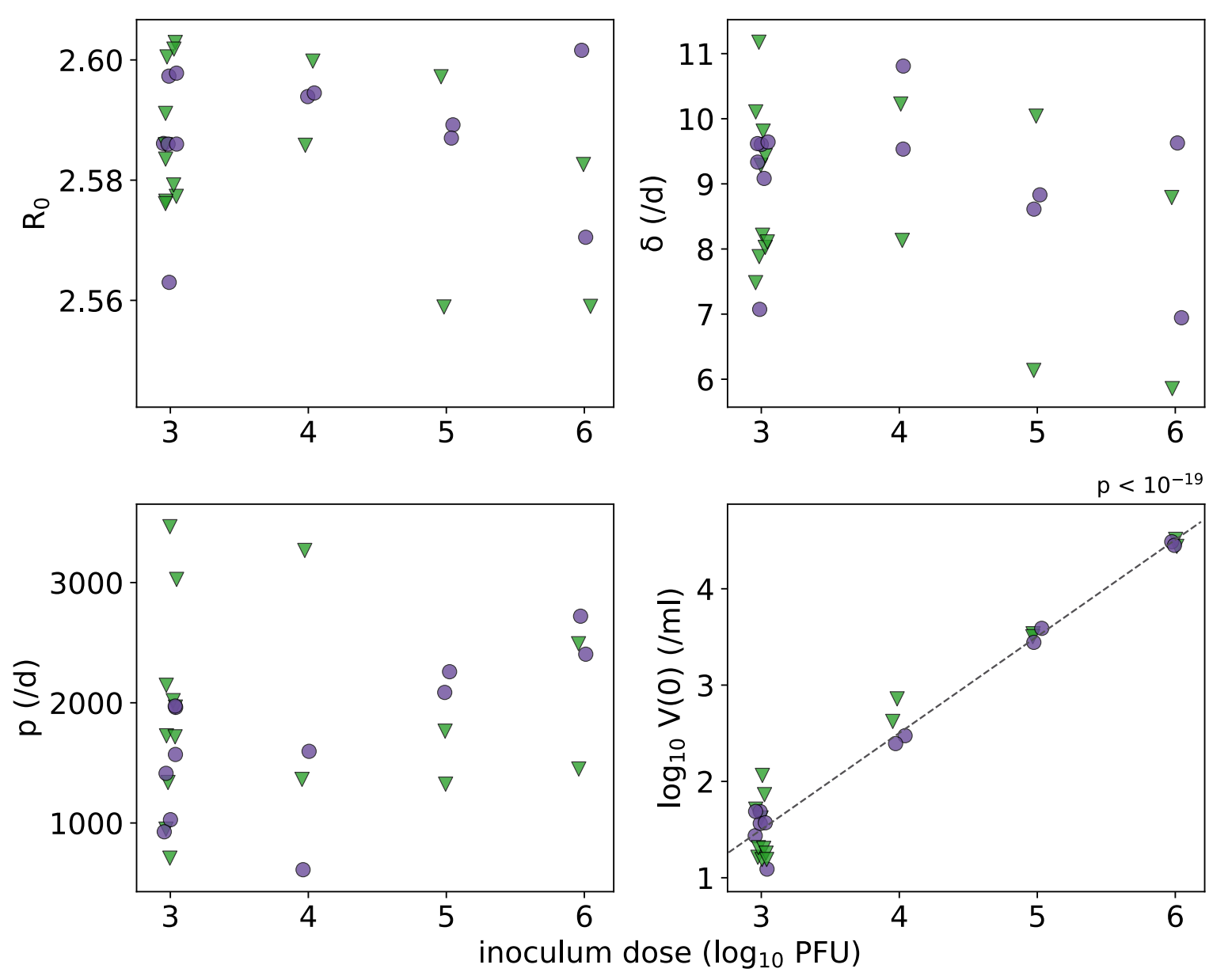

\title{
Supplementary Figure 7
}

Relationships between individual estimated parameters and inoculum dose, with individual estimated parameters from the target cell limited model (Eq. 1) with fixed $k=8 \mathrm{~d}^{-1}$ and fixed $c=$ $10 \mathrm{~d}^{-1}$ and with a dose-dependency in $\log _{10} V_{0}$ explicitly incorporated (Table 1). Correlations between parameters and inoculum dose are assessed via the Pearson correlation, and where this is significant after Bonferroni correction the linear regression line is shown (dashed) and the $p$-value is shown above the panel. Markers for individual animals are colored by the viral strain (BR: green triangles, PR: purple circles). 